\title{
Maintenance and symptom relief with budesonide plus formoterol reduced severe asthma exacerbations
}

O'Byrne PM, Bisgaard H, Godard PP, et al. Budesonide/formoterol combination therapy as both maintenance and reliever medication in asthma. Am J Respir Crit Care Med 2005;171:129-36.

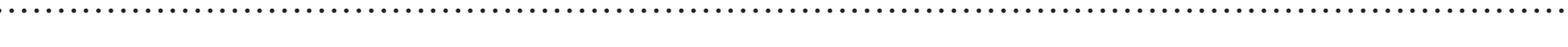

In patients with asthma, is budesonide (BUD) plus formoterol (FORM) (BUDFORM) for both maintenance and symptom relief more effective than fixed dosing using BUDFORM or a 4 fold higher dose of BUD, both with a short acting $\beta_{2}$ agonist (SABA), for reducing the rate of severe asthma exacerbations?

\section{METHODS}

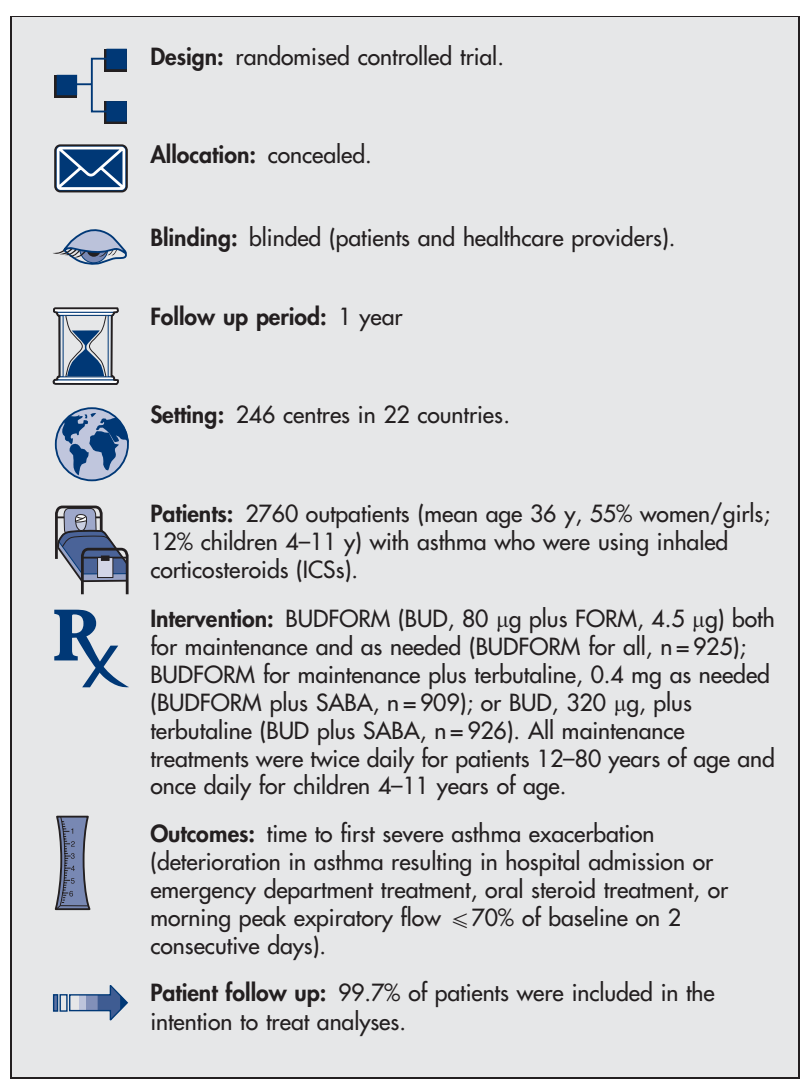

\section{MAIN RESULTS}

Time to first severe exacerbation was longer in the BUDFORM-for-all group than in the BUDFORM plus SABA group or BUD plus SABA group ( $\mathrm{p}$ values $<0.001$ ). Fewer patients in the BUDFORM-for-all group than in the BUDFORM plus SABA group or BUD plus SABA group had $\geqslant 1$ severe asthma exacerbation (table).

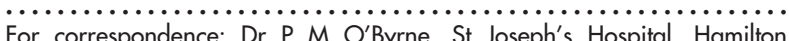
Ontario, Canada. obyrnep@mcmaster.ca

Source of funding: AstraZeneca R\&D, Lund, Sweden.

\section{CONCLUSION}

In patients with asthma, budesonide plus formoterol (BUDFORM) for both maintenance and symptom relief was more effective than fixed dosing using BUDFORM or a 4 fold higher dose of budesonide, both with a short acting $\beta_{2}$ agonist, for reducing severe asthma exacerbations.

A modified version of this abstract appears in Evidence-Based Medicine.

\section{Commentary}

A cute asthma exacerbations are a major cause of morbidity for patients of all ages but can be successfully managed with treatment plans that include long acting $\beta$ agonists (LABAs) and ICSs. The trial by $O^{\prime} B r y n e$ et al is one of the first to examine the effect of a combination of an LABA and an ICS inhaler for use on a maintenance and as needed basis in patients of all ages.

Study treatments were guided by patient age group: 4-11 and 12-80 years. The latter group, however, is not truly reflective of adults because it includes adolescents, young and middle aged adults, and the elderly. Each of these groups has different physiological pharmacokinetics such as rates of absorption and metabolism. Generalised dosing is contrary to the Global Initiative for Asthma ${ }^{1}$ recommendation of individualised dosing, especially at either end of the age spectrum. In addition, use of terbutaline as an SABA has declined in the US and the safety of its use in children $<12$ years of age is not established. ${ }^{2}$ Therefore, the interventions may not be broadly reflective of practice and might preclude wide application of results to all clinical settings.

However, the results have important implications for nurses and advanced practice nurses. Using an LABA (with properties for both maintenance and quick relief) plus an ICS addresses the antiinflammatory and bronchodilator needs of patients with asthma in one medication. A patient's ability to increase the dose of both can result in less use of systemic steroids, less frequent exacerbations, and less expensive medical interventions.

Susan A Bruce, RN, MS, NP Yvonne K Scherer, RN, EdD, CNS University at Buffalo Buffalo, New York, USA

1 Global Initiative for Asthma (GINA). Global strategy for asthma management and prevention: WHO/NHLBI Workshop report. Bethesda, MD: National Institutes of Health, 1995. Publication Number 02-3659. Updated 2002; Management segment (Ch7) updated 2004. http:// www.ginasthma.org

$2 \mathrm{http}: / /$ www. healthdigest.org/drugs/terbutalinesulfate.html. Accessed 2 May, 2005.

Budesonide (BUD) plus formoterol (FORM) for both maintenance and symptom relief (BUDFORM for all) $v$ fixed dosing using BUDFORM or a 4 fold higher dose of BUD, both with a short acting $\beta_{2}$ agonist (SABA) in asthma*

\begin{tabular}{|c|c|c|c|c|}
\hline Outcome at 1 year & Comparisons & Event rates & $\operatorname{RRR}(95 \% \mathrm{Cl})$ & NNT (Cl) \\
\hline $\begin{array}{l}\geqslant 1 \text { severe asthma } \\
\text { exacerbation }\end{array}$ & $\begin{array}{l}\text { BUDFORM for all } v \text { BUDFORM plus SABA } \\
\text { BUDFORM for all } v \text { BUD plus SABA }\end{array}$ & $\begin{array}{l}16 \% \vee 27 \% \\
16 \% \vee 28 \%\end{array}$ & $\begin{array}{l}41 \%(30 \text { to } 52) \\
43 \%(31 \text { to } 53)\end{array}$ & $\begin{array}{r}10(8 \text { to } 13) \\
9(7 \text { to } 12)\end{array}$ \\
\hline
\end{tabular}

*Abbreviations defined in glossary; RRR, NNT, and Cl calculated from Cox proportional hazard ratios in article. 